\title{
Interannual variability of the Antarctic Circumpolar Current strength based on merged altimeter data
}

\author{
ZHANG LinLin, SUN Che ${ }^{*} \&$ HU DunXin \\ Key Laboratory of Ocean Circulation and Waves, Institute of Oceanology, Chinese Academy of Sciences, Qingdao 266071, China
}

Received November 11, 2011; accepted January 13, 2012; published online March 23, 2012

Interannual variability of the Antarctic Circumpolar Current (ACC) strength is studied in stream-coordinate with twenty-year Absolute Dynamic Topography data from satellite altimetry. The stream-coordinate projection method separates the ACC from adjacent subtropical and subpolar gyres, enabling consideration of the zonal asymmetry of the ACC rather than assuming that the ACC is a purely zonal flow. It is shown that the ACC strength has large interannual variations with two recent peaks around 2000 and 2009. The interannual variability appears mainly in the Indo-Pacific sector of the Southern Ocean and the strongest signal is located south of Australia. The intensification of the westerly wind in 1998 and 2008 appears to cause the strengthening of the ACC via baroclinic processes.

ACC strength, interannual variability, stream-coordinate, altimetry, westerly wind

Citation: Zhang L L, Sun C, Hu D X. Interannual variability of the Antarctic Circumpolar Current strength based on merged altimeter data. Chin Sci Bull, 2012, 57: 2015-2021, doi: 10.1007/s11434-012-5040-3

The Antarctic Circumpolar Current (ACC) connects the world's three major ocean basins and is a key element in the global thermohaline circulation. The inter-basin exchange provided by the ACC redistributes heat, salt and other properties in the world's ocean. Therefore, changes in the ACC exert significant influences on the global climate system. Much work has attempted to quantify the transport and variability of the ACC based on hydrography and numerical models. The Dynamic Response and Kinematics Experiment, 1979 (DRAKE 79) monitored the ACC transport through Drake Passage with current meter moorings and pressure gauges [1]. Rintoul and Sokolov [2] examined the baroclinic transport variability of the ACC south of Australia with World Ocean Circulation Experiment (WOCE) SR3 repeat sections. Based on numerical models, the seasonal and interannual variability of the ACC transport was ascribed to the atmospheric forcing in the form of the Southern Hemisphere Annular Mode (SAM) [3-6].

The meridional sections at the Southern Ocean choke

*Corresponding author (email: csun@qdio.ac.cn) points such as the SR3 line, contain subtropical and subpolar components [7] (Figure 1), and therefore zonal transport estimates by previous studies are strongly influenced by adjacent subtropical and subpolar gyres and cannot solely represent the strength of the ACC. Moreover, the data sets used in previous studies are insufficient to map the interannual variability of the ACC, and sampling with a frequency significantly higher than weekly is required to obtain reliable estimates of the ACC variability at interannual periods [8]. Therefore, limited by the in-situ observations and data processing methods, few extant studies give reliable estimates of the interannual variability of the ACC strength.

Recently a stream-coordinate method was developed to study the ACC by projecting hydrographic data into a stream function space [7,9]. The method isolates the ACC from its adjacent subtropical and subpolar gyres. It also considers the zonal asymmetry of the ACC path rather than simply assume that the ACC is a purely zonal current. It was found that the baroclinic structure and baroclinic transport of the ACC were very stable. But given a constant volume transport, the ACC strength can still change due to 


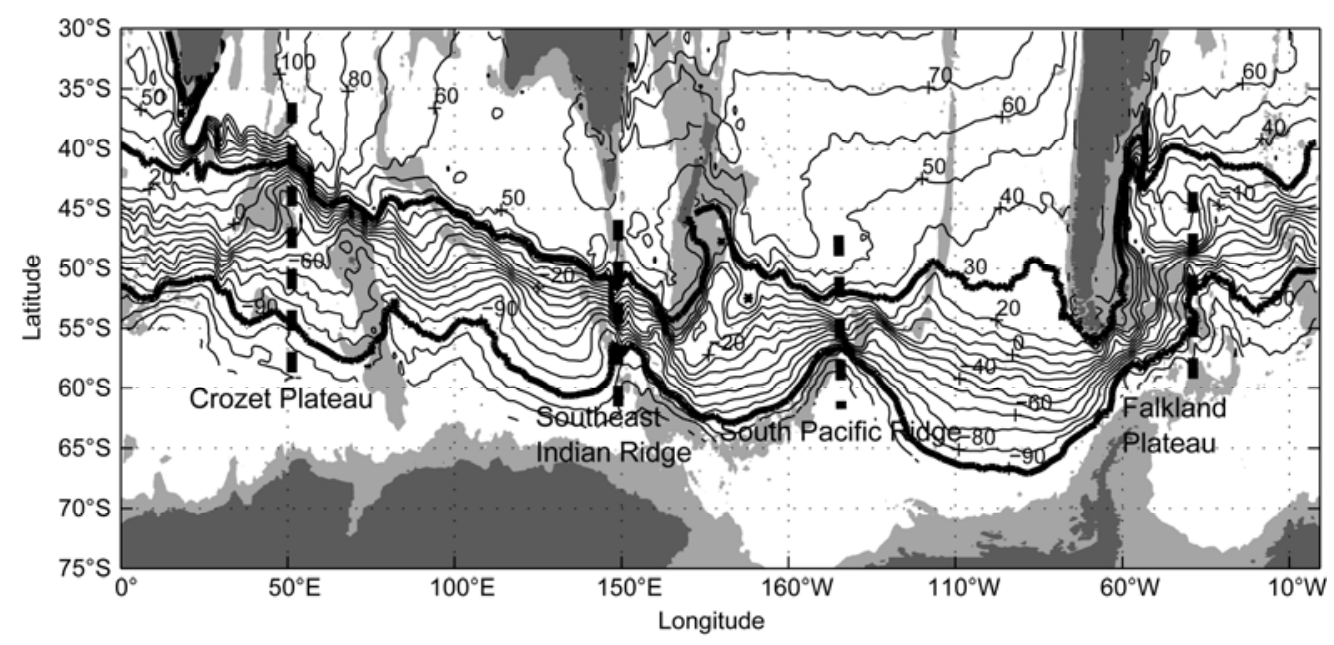

Figure 1 Mean SSH (cm) during 1993-2011 from AVISO (contours). Bold contours represent the northernmost and southernmost streamlines that pass through Drake Passage. Depths less than $3000 \mathrm{~m}$ are gray shaded. Dashed lines indicate four regions where the ACC strength has large interannual variations, as described in section 3 .

the merging and splitting of streamlines (Figure 2).

Satellite altimetry has provided continuous global coverage of sea surface heights (SSH) from 1992 to the present. This is potentially useful for examining the interannual variability of the ACC. Previous studies with satellite altimetry are often focused on oceanic current anomalies because of the difficulty of determining the geoid with sufficient accuracy. This difficulty has been addressed by the satellite mission Gravity Recovery and Climate Experiment (GRACE), based on which a new product of Absolute Dynamic Topography (ADT) was produced by the French Archiving, Validation and Interpretation of Satellite Oceanographic Data (AVISO) project by combining altimetry, hydrography

(a)

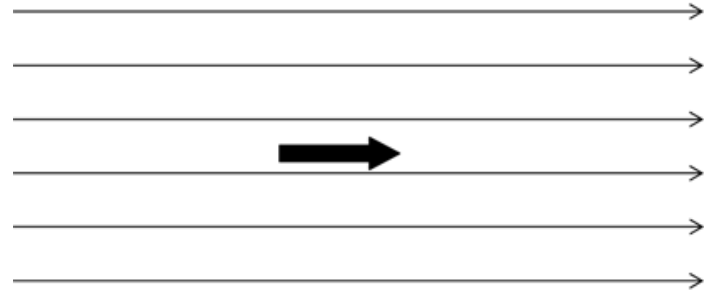

(b)

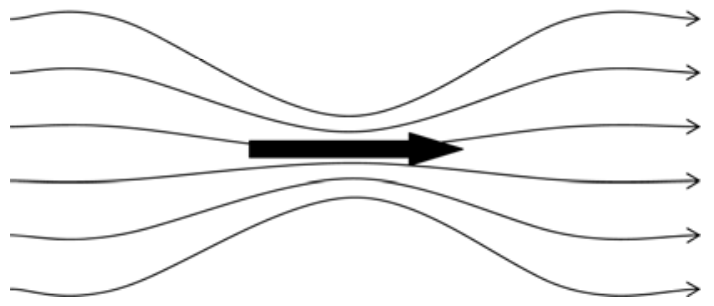

Figure 2 Definition of jet strength based on jet speed rather than volume flux. The ACC volume transport in this idealistic case is constant, but its strength varies. (a) The ACC weakens with streamlines being sparse; (b) the ACC strengthens with streamlines merging into a strong jet. and the latest geoid model [10].

Sun et al. [11] have validated the ADT product with a two-year mooring observation south of Australia. They used the stream-coordinate method to study the spatio-temporal variability of the ACC jet structure. In this study we further examine the interannual variability of the ACC strength based on the ADT data and explore its relationship with the westerly wind.

\section{Data and methods}

\subsection{Data description}

The ADT data from AVISO are used in this study. The ADT data consist of a mean dynamic topography and merged sea level anomalies (SLA). The mean dynamic topography is estimated from the combination of the latest geoid model, altimetric mean sea surface heights and in-situ measurements with an inverse technique [10]. The SLA is derived from Topex/Poseidon, Jason-1 and ERS altimeter observations using a mapping method [12]. The data are interpolated onto a global grid of $0.25^{\circ}$ resolution between $82^{\circ} \mathrm{S}$ and $82^{\circ} \mathrm{N}$ and are archived in weekly averaged frames (available from October 1992 to the present). The tidal and sea level pressure corrections are incorporated into the data.

Geostrophic currents are calculated from the ADT data. The results have been compared with drifter measurements, and the rms residual is less than $13 \mathrm{~cm} / \mathrm{s}$ in the global ocean. The mapped data combine measurements from ascending, descending, and neighboring tracks and are able to estimate the geostrophic currents better than the along-track data.

\subsection{Stream-coordinate projection method}

To obtain the mean velocity structure of the ACC, a streamwise approach is preferred because averaging in geographical 
space tends to yield a broader and weaker profile as the main axis of the ACC shifts laterally and meanders constantly. In contrast, location in stream-coordinates is defined not by distance but by a streamfunction parameter such as $\mathrm{SSH}$ or geopotential. The meso-scale meander we see in geographical space does not contaminate a streamwise mean because streamfunction is tightly related to the velocity structure of the ACC $[13,14]$. The ACC is not a purely zonal current, and zonal averaging of its velocity is influenced strongly by the subtropical and subpolar gyres. In stream-coordinate, the ACC is averaged along streamlines, which enables separation of the ACC from adjacent gyres and gives relatively reliable estimates.

We chose SSH from ADT data as the projection parameter of the stream-coordinate [11]. At each longitude, weekly geostrophic speed profiles were projected onto the SSH coordinate using linear interpolation. A regional-mean annual cycle around $5 \mathrm{~cm}$ magnitude has been subtracted from the SSH data to eliminate the influence of the seasonally varying steric height. To avoid the multi-value scenario caused by meandering jets, grid points with westward flow are also excluded from the calculation. The resultant speed profile represents the jet structure of the ACC in streamcoordinate, and can also be regarded as a streamwise kinetic energy spectrum. The ACC strength is then defined as the mean speed between the northernmost and southernmost streamlines that pass through Drake Passage (Figure 1). The strength defined here is different from the volume transport. The strength is likely to vary with time through merging and splitting of streamlines while the volume transport stays constant (Figure 2).

Based on a near-eddy-resolving model, Ivchenko et al. [15] used streamwise coordinate to study the velocity structure of the ACC. The time-averaged barotropic streamline coordinate allowed them to consider the zonal asymmetry of the ACC path but ignore its meridional shifts with time. The stream-coordinate projection method used here enables us to consider not only the spatial asymmetry of the ACC but also its temporal shifts. It removes influences from mesoscale meanders and adjacent gyres of the ACC, and therefore is able to provide a reliable estimate of the ACC strength. The spatio-temporal variability of the ACC strength in stream-coordinate is examined below.

\section{Results}

Figure 3(a) shows the interannual variation of the circumpolar mean speed of the ACC in stream-coordinate during 1993-2011. The axis of the ACC corresponds to a SSH value of around $-20 \mathrm{~cm}$, and exhibits a trend of moving from low to high $\mathrm{SSH}$ values during these years. This trend is probably related to sea level rise in the Southern Ocean. The ACC mean speed also exhibits an increasing trend accompanied by large interannual variations. The linear trend of axial speed is around $0.07 \mathrm{~cm} / \mathrm{s}$ per year. On interannual time scale, the ACC was strong around 2001 and 2009 with axial speeds up to $32 \mathrm{~cm} / \mathrm{s}$. It was relatively weak in 1994 with an axial speed of $30 \mathrm{~cm} / \mathrm{s}$. The amplitude of the interannual variation of the ACC axial speed is around $2 \mathrm{~cm} / \mathrm{s}$, which is twice as larger as that of the seasonal variation (not shown). In the calculation of the interannual variation, the linear trend was not removed because it is only about $10 \%$ of the magnitude of the interannual variation.

To check whether the interannual signal of the ACC strength holds on the circumpolar scale, we calculated the ACC strength at different longitudes (Figure 3(b)). In the Indo-Pacific sector, the interannual variation of the ACC strength is generally uniform. The ACC strengthened during 2000-2001 and 2009 with the strongest interannual signal appearing at $150^{\circ} \mathrm{E}$. However, there are still some differences between Pacific and Indian sectors. The strengthening of the ACC in the Indian Ocean occurred in 2000, a little earlier than that in the Pacific Ocean where the ACC strengthened in 2001. In the Atlantic sector, the interannual variation of the ACC strength is entirely different from the above two sectors, exhibiting an increasing trend from 1993 to 2011. Besides the interannual signal at different longitudes, we also examined the interannual variation of the ACC strength in different months (Figure 3(c)). First, we calculated the monthly mean strength of the ACC for each of the 228 months during 1993-2011. Then we took out the strength in one month and obtained the interannual variation of the ACC strength for that particular month. The results show that the interannual signal is similar across the year with the ACC strengthening around 2000 and 2009, and weakening in 1994. But signals during October-December are a little different from those during other months. Though the ACC was strong around 2000 and 2009, it also strengthened during October-December of 2006 and 2008.

To illustrate the interannual variation of the ACC strength further, we calculated the kinetic energy of the ACC in different years under geographical coordinate (Figure 4). The strengthening of the ACC around 2000 is coherent in the circumpolar extent except in the southwest Atlantic. The maximum strengthening is located in regions south of Australia and New Zealand, as shown by the rectangle in Figure 4. The high kinetic energies around 2000 are concentrated in a circumpolar band along the ACC. Within this band, the kinetic energy values are elevated by around $50-100 \mathrm{~cm}^{2} / \mathrm{s}^{2}$, roughly to $5 \%-10 \%$ of its long-term mean. In addition, there appears to be a slowly increasing trend in the ACC kinetic energy from 1993 to 2011, especially in the south Atlantic (not shown). All of these features are consistent with the results in stream-coordinate. Meredith and Hogg [16] found that anomalously high eddy kinetic energy appeared in the ACC during the period 2000-2002 based on the altimetric sea level anomaly data from 1993 to 2004. In this study, stream-coordinate analysis with the latest ADT data shows that the ACC strength also 

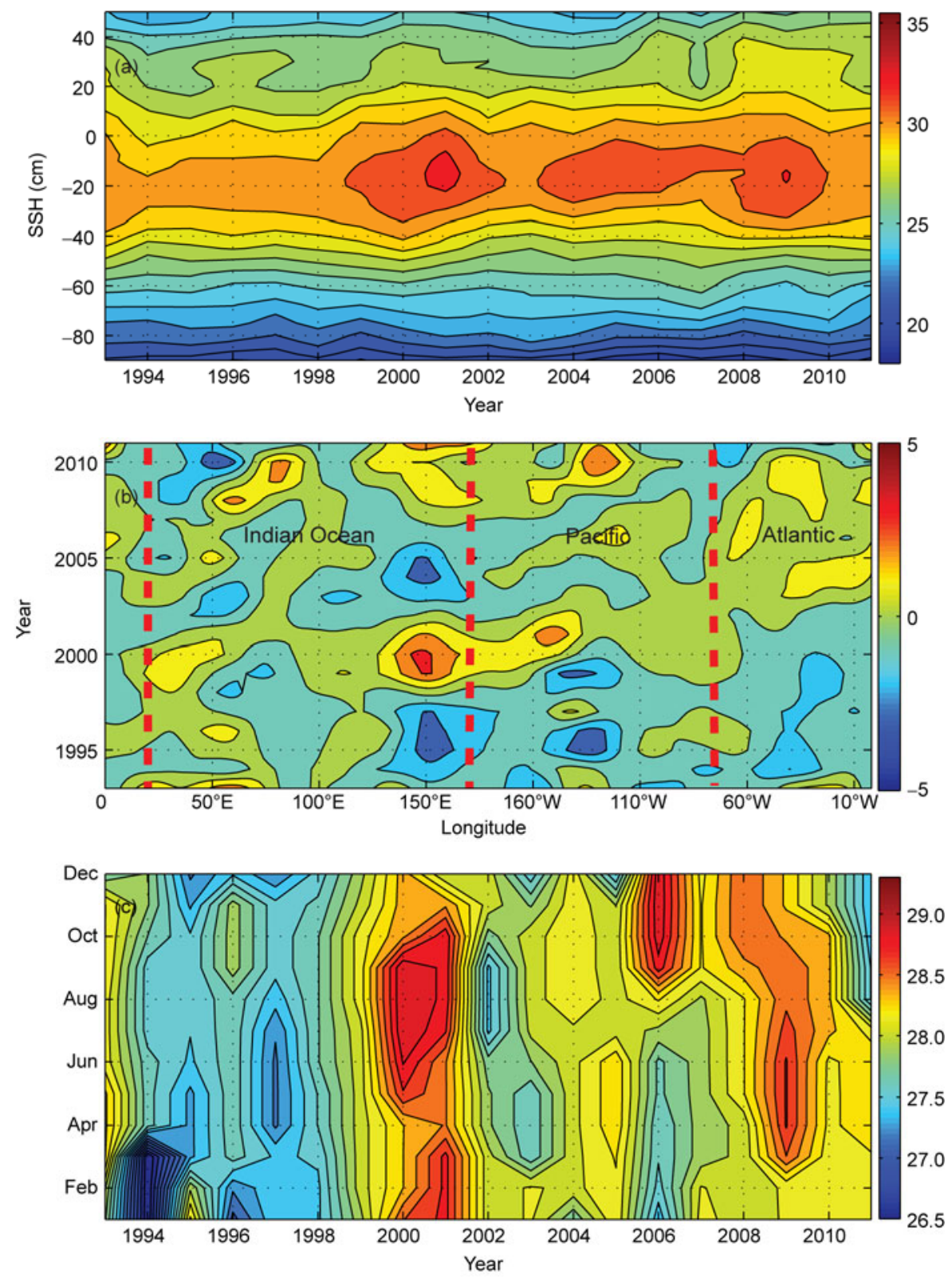

Figure 3 (a) Circumpolar mean speed (cm/s) of the ACC in stream-coordinate from 1993 to 2011; (b) interannual variation of the ACC strength (cm/s) at different longitudes (the temporal mean has been removed); (c) interannual variation of the ACC strength $(\mathrm{cm} / \mathrm{s})$ in different months.

increased around 2000. Moreover, the ACC strengthened in 2009 and weakened in 1994

\section{Discussion}

Figure 5(a) shows the standard deviation of annual mean strength of the ACC at different longitudes. There are four places with large interannual variability and strong mean flow, all of which located downstream of major meridional ridges (Figure 1). As the ACC crosses submarine ridges it strengthens because of conversion of potential energy to kinetic energy, consistent with Gille [17] and Sallee et al.
[18]. Among these four regions, the one south of Australia has the largest interannual variation with standard deviation reaching $3.5 \mathrm{~cm} / \mathrm{s}$ and accounting for $40 \%$ of the total temporal variance.

Wind stress is one of the most important driving forces for the oceanic circulation. The ACC responds to changes in the zonal wind stress, and the response contains both barotropic and baroclinic processes [19,20]. In previous studies the SAM has been identified as the dominant mode of atmosphere variability with a zonally-symmetric dipole structure in the Southern Hemisphere [21]. Meredith et al. [4] presented observational evidence that interannual changes of the oceanic transport through Drake Passage were forced 

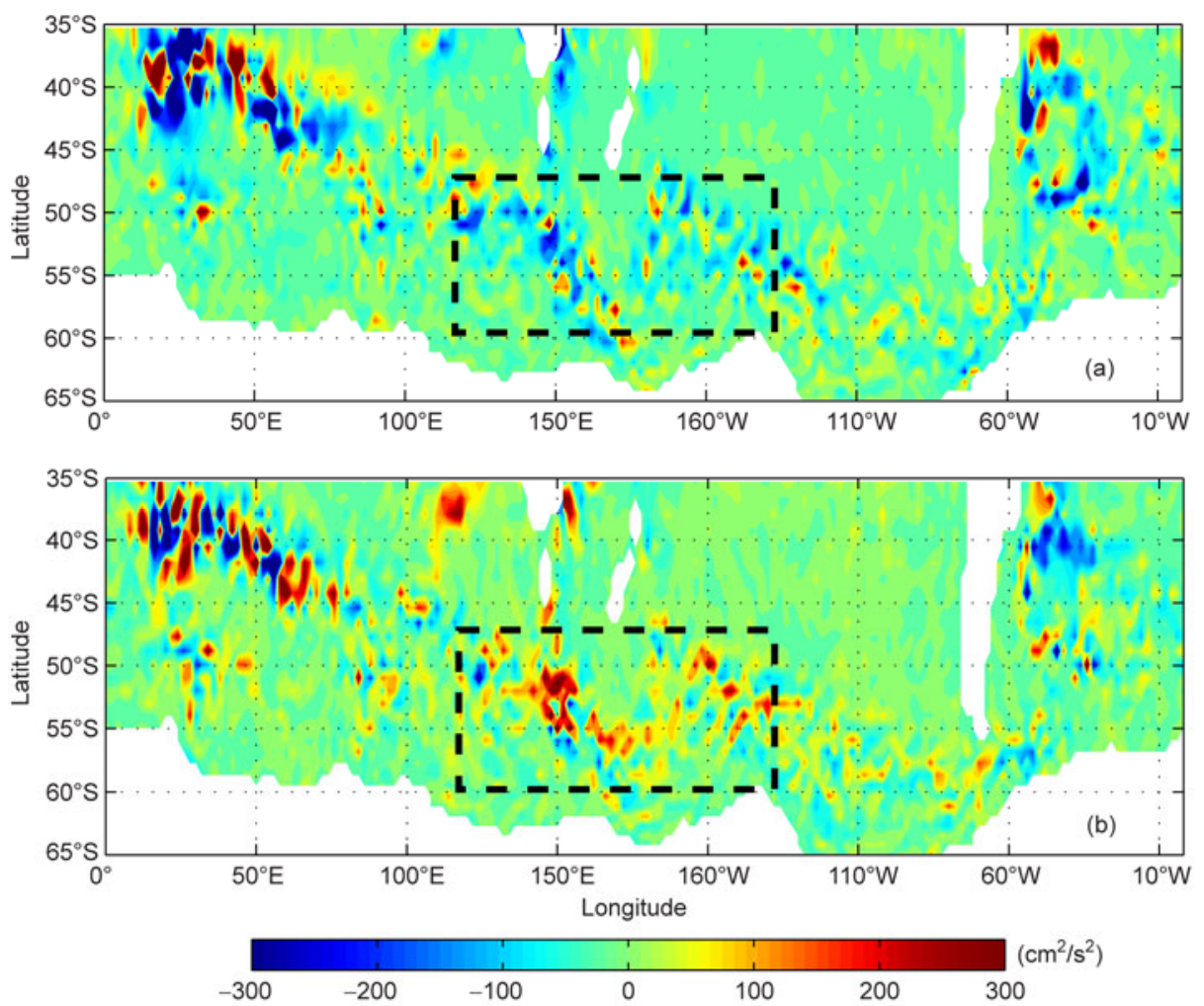

Figure 4 Two-year mean kinetic energy of the ACC during 1994-1995 (a) and 2000-2001 (b). The temporal mean during 1993-2011 has been removed.
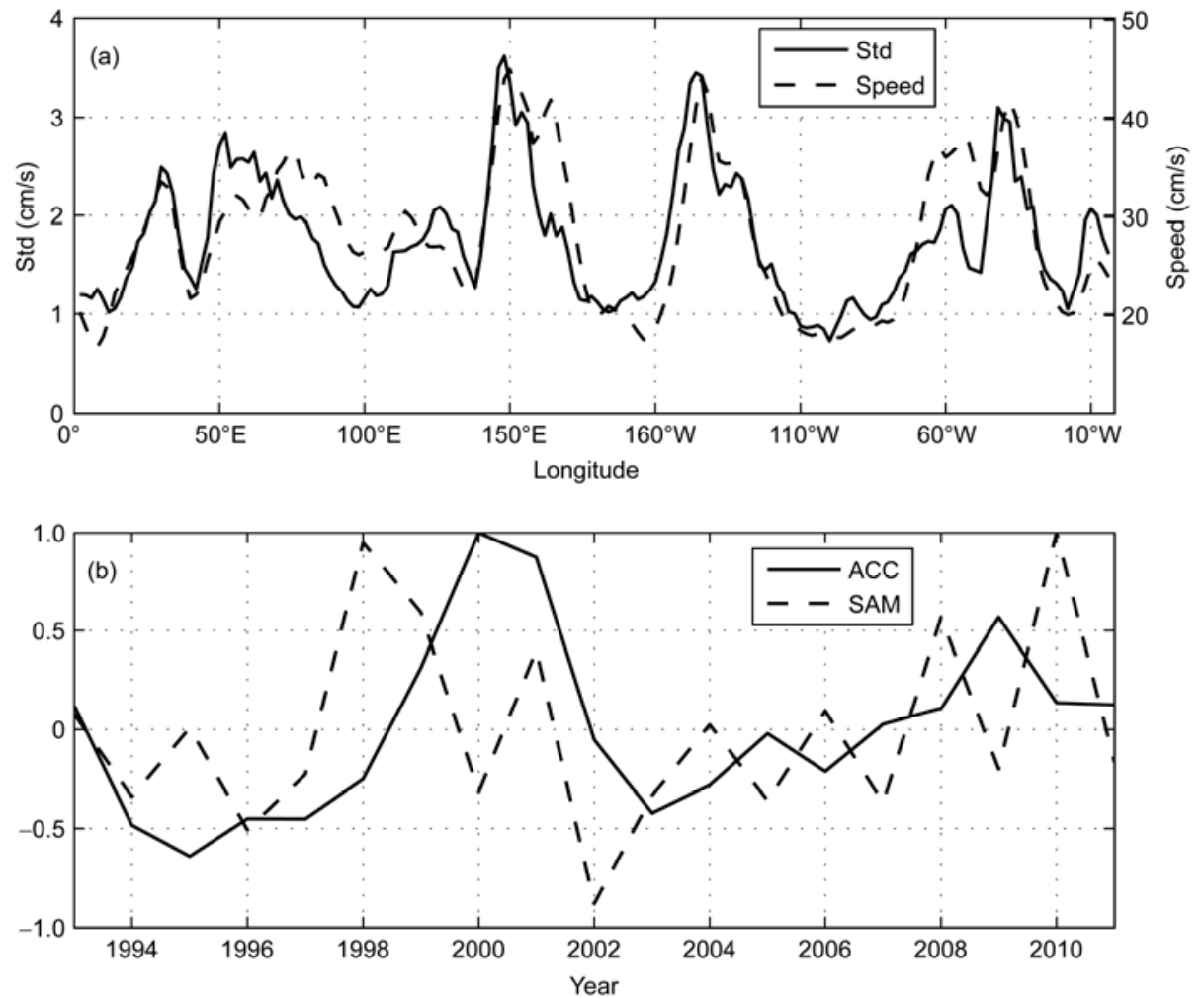

Figure 5 (a) Standard deviation of the annual mean strength of the ACC at different longitudes (solid line) and the temporal mean strength of the ACC during 1993-2011 (dashed line); (b) normalized annual mean strength of the ACC in the Indo-Pacific sector (solid line) and annual mean SAM index (dashed line) from 1993 to 2011. The linear correlation between SAM and the ACC strength is insignificant at the 95\% confidence level with zero lag and significant with 1-2 years lag. SAM leads the ACC strength by 1-2 years with a correlation of 0.50 . 
by SAM variability. Yang et al. [22] studied the interannual variability of the ACC transport with model outputs and proposed a mechanism of delayed response to the SAM. Treguier et al. [6] evaluated the response of the Southern Ocean to the variability of the SAM with a global eddy-permitting model and confirmed the correlation between the ACC transport and the SAM on interannual time scales. While these studies were all focused on the ACC transport, we here discuss the impact of SAM variability on the ACC strength.

Figure 5(b) shows the interannual variation of the ACC strength and the SAM index during 1993-2011. The SAM index used here is derived from the National Center for Environmental Prediction and National Center for Atmospheric Research (NCEP-NCAR) reanalysis fields. It is defined as the difference in the normalized monthly zonal mean sea level pressure between $40^{\circ} \mathrm{S}$ and $70^{\circ} \mathrm{S}$ [23]. There are large interannual variations in the SAM index with positive SAM events occurring in 1998, 2008 and 2010. Such interannual variation of the SAM has a close relationship with eddy-driven zonal wind anomalies that are induced by the ENSO and extend into the mid-high latitudes [24,25]. In the figure a positive lag-correlation exists between the SAM index and the ACC strength with the SAM leading the ACC by $1-2$ years. The lag-correlation coefficient is 0.5 and significant at the $95 \%$ confidence level. The strengthening of the ACC around 2000 and 2009 appears to be driven by the intensification of the westerly wind in 1998 and 2008, respectively.

Meredith and Hogg [16] and Hogg and Blundell [26] used an eddy-resolving ocean model to simulate the response of the ACC to the zonal wind stress and found that there was a lag between the wind stress forcing and the ACC kinetic energy of approximately 2 years, which was consistent with the results of this study. The delayed re- sponse is related to the internal variability of the ACC. The wind energy input is initially stored as potential energy, and tilting isopycnal surfaces then become baroclinically unstable while meso-scale eddies begin to transfer momentum from the upper ocean to the deep ocean via interfacial form stress, subjecting the ACC to strong topographic steering. The steered flow becomes more baroclinically unstable and produces more meso-scale eddies. The potential energy is thus transferred to kinetic energy, and the ACC strengthens over several years until excess potential energy is drained. As shown in Figure 5(b), the strengthening of the ACC around 2000 and 2009 lags the intensification of the westerly wind in 1998 and 2008 respectively, and their time lags seem to vary. In the future study we will use numerical simulations to investigate how internal oceanic processes influence the response time of the ACC.

Though the ACC strengthened around 2000 and 2009 to an almost circumpolar extent, the interannual variation of the ACC strength in the south Atlantic is different from other sectors and exhibits an increasing trend from 1993 to 2011 as shown in Figures 3 and 4. To explain such a spatial difference, we calculated the interannual variation of the westerly wind at different longitudes (Figure 6). The most significant feature of the westerly variation is its strengthening in 1998, 2008 and 2010, which is consistent with the SAM index. Moreover, the interannual variation of the westerly wind varies in different basins. The large variation is located in the Indo-Pacific sector between $130^{\circ} \mathrm{E}$ and $90^{\circ} \mathrm{W}$, coinciding with the region of the strong interannual variation of the ACC strength. This suggests that the ACC variation is indeed driven by the westerly wind. In the Atlantic sector, the variation of the westerly wind is different from other sectors and exhibits a weakening trend, in contrast with the increasing trend of the ACC strength in this sector. Therefore, the variation of the ACC strength in the

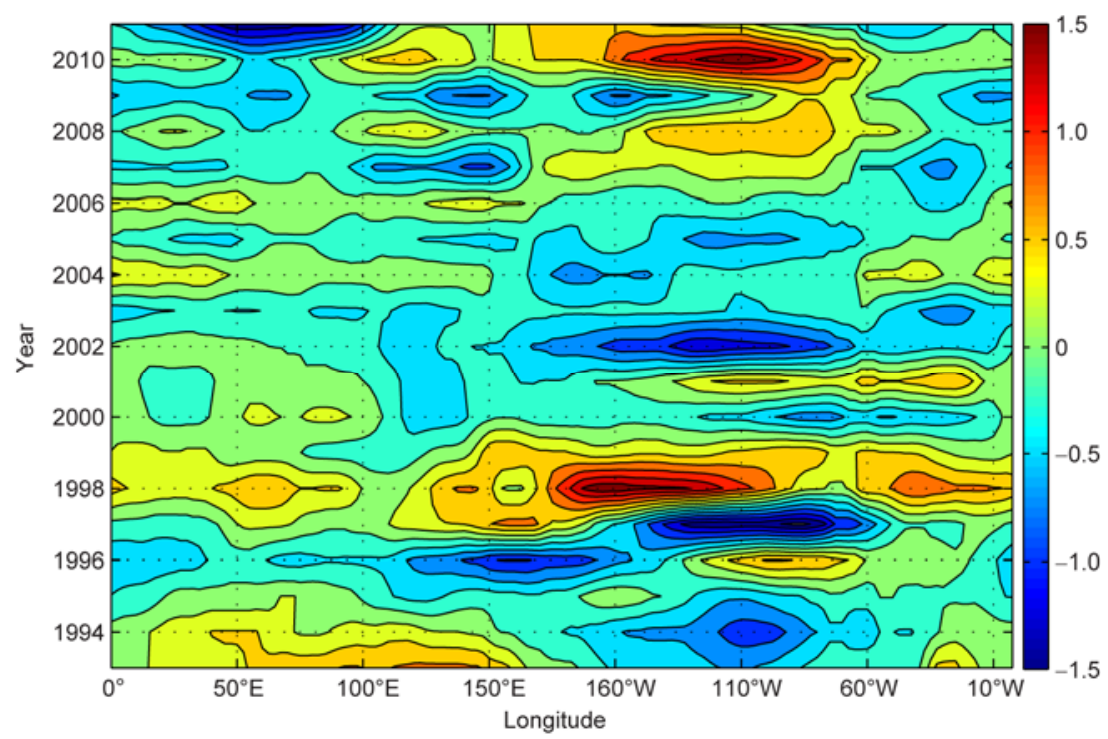

Figure 6 Meridional mean speed (m/s) of the westerly wind between $40^{\circ}$ and $65^{\circ} \mathrm{S}$ during $1993-2011$. 
South Atlantic cannot be simply attributed to westerly winds, and it probably depends on the complex interplay between wind forcing and inflow from subtropical gyres [27].

The ACC is a key element in the global climate system and its long-term change has a broad effect. With the SAM shifting toward a higher index state over the past several decades due to the Antarctic ozone depletion, the westerly wind stress over the Southern Ocean exhibits a strengthening trend [28]. The response of the ACC strength to this trend remains to be explored in further studies.

The authors would like to thank the two anonymous reviewers for their valuable suggestions and comments. This work was supported by the Knowledge Innovation Program of Chinese Academy of Sciences (KZCX2$Y W-Q 11-02)$ and the National Natural Science Foundation of China (41006114 and 40890151).

1 Whitworth T, Peterson R. Volume transport of the Antarctic Circumpolar Current from bottom pressure measurements. J Phys Oceanogr, 1985, 15: 810-816

2 Rintoul S, Sokolov S. Baroclinic transport variability of the Antarctic Circumpolar Current south of Australia (WOCE repeat section SR3). J Geophys Res, 2001, 106: 2815-2832

3 Shi J, Le K, Choi B. The pattern and seasonal variation of the circulation in the region of the Kerguelen Plateau (in Chinese). Acta Oceanol Sin, 2002, 24: 11-22

4 Meredith M, Woodworth P, Hughes C, et al. Changes in the ocean transport through Drake Passage during the 1980s and 1990s, forced by changes in the Southern Annular Mode. Geophys Res Lett, 2004, 31: L21305

5 Yang X, Wang D, Wang J, et al. Connection between the decadal variability in the Southern Ocean circulation and the Southern Annular Mode. Geophys Res Lett, 2007, 34: L16604

6 Treguier A, Sommer J, Molines J, et al. Response of the Southern Ocean to the Southern Annular Mode: Interannual variability and multidecadal trend. J Phys Oceanogr, 2010, 40: 1659-1668

7 Sun C, Watts D. Heat flux carried by the Antarctic Circumpolar Current mean flow. J Geophys Res, 2002, 107: 3119

8 Meredith M, Hughes C. On the sampling timescale required to reliably monitor interannual variability in the Antarctic circumpolar transport. Geophys Res Lett, 2005, 32: L03609

9 Sun C, Watts D. A circumpolar gravest empirical mode for the Southern Ocean hydrography. J Geophys Res, 2001, 106: 2833-2855

10 Rio M, Hernandez F. A mean dynamic topography computed over the world ocean from altimetry, in situ measurements and a geoid model. J Geophys Res, 2004, 109: C12032

11 Sun C, Zhang L, Yan X. Stream-coordinate structure of oceanic jets based on merged altimeter data. Chin J Oceanol Limnol, 2011, 29: 1-9

12 Ducet N, Le Traon P, Reverdin G. Global high resolution mapping of ocean circulation from Topex/Poseidon and ERS-1 and -2. J Geophys Res, 2000, 105: 19477-19498

13 Meinen C, Luther D, Watts D, et al. Mean stream coordinates structure of the Subantarctic Front: Temperature, salinity, and absolute velocity. J Geophys Res, 2003, 108: 3263

14 Zhang L, Sun C. A geostrophic empirical mode based on altimetric sea surface height. Sci China Ser D-Earth Sci, 2011, doi:10.1007/s 11430-011-4293-z

15 Ivchenko V, Richards K, Stevens D. The dynamics of the Antarctic Circumpolar Current. J Phys Oceanogr, 1996, 26: 753-774

16 Meredith M, Hogg A. Circumpolar response of Southern Ocean eddy activity to a change in the Southern Annular Mode. Geophys Res Lett, 2006, 33: L16608

17 Gille S. Mean sea surface height of the Antarctic Circumpolar Current from Geosat data: Method and application. J Geophys Res, 1994, 99: 18255-18273

18 Sallee J, Speer K, Morrow R. Response of the Antarctic Circumpolar Current to atmospheric variability. J Clim, 2008, 21: 3020-3039

19 Olbers D, Lettmann K. Barotropic and baroclinic processes in the transport variability of the Antarctic Circumpolar Current. Ocean Dyn, 2007, 57: 559-578

20 He Z, Dong Z, Pu S. Seasonal variations of the front paths and wind field in the Southeast Indian Ocean and their relations (in Chinese). Acta Oceanol Sin, 2007, 29: 18-24

21 Thompson D, Wallace J. Annular modes in the extratropical circulation, part I: Month-to-month variability. J Clim, 2000, 13: 1000-1016

22 Yang X, Huang R, Wang J, et al. Delayed baroclinic response of the Antarctic Circumpolar Current to surface wind stress. Sci China Ser D-Earth Sci, 2008, 51: 1036-1043

23 Nan S, Li J. The relationship between summer precipitation in the Yangtze River valley and the previous Southern Hemisphere Annular Mode. Geophys Res Lett, 2003, 30: 2266

24 L'Heureux M, Thompson D. Observed relationships between the El Nino-Southern Oscillation and the extratropical zonal-mean circulation. J Clim, 2006, 19: 276-287

25 Carvalho L, Jones C, Ambrizzi T. Opposite phases of the Antarctic Oscillation and relationships with intraseasonal to interannual activity in the tropics during the austral summer. J Clim, 2005, 18: 702-718

26 Hogg A, Blundell J. Interdecadal variability of the Southern Ocean. J Phys Oceanogr, 2006, 36: 1626-1645

27 Morrow R, Ward M, Hogg A, et al. Eddy response to Southern Ocean climate modes. J Geophys Res, 2010, 115: C10030

28 Yang X, Huang R, Wang D. Decadal changes of wind stress over the Southern Ocean associated with Antarctic ozone depletion. J Clim, 2007, 20: 3395-3410

Open Access This article is distributed under the terms of the Creative Commons Attribution License which permits any use, distribution, and reproduction in any medium, provided the original author(s) and source are credited. 